\title{
Adherence to Malaria Preventive Measures and Associated Factors in Badewacho District, Southern Ethiopia
}

\author{
Koyamo Darfiro ${ }^{1}$, Berhanu Erko ${ }^{2}$, Abebe Animut ${ }^{2}$, Adugna Endale ${ }^{3, \text { * }}$ \\ ${ }^{1}$ West Badewacho Woreda Health Office, Hadiya Zone, Southern Nations, Nationalities, and Peoples' Region, Ethiopia \\ ${ }^{2}$ Aklilu Lemma Institute of Pathobiology, Addis Ababa University, Addis Ababa, Ethiopia \\ ${ }^{3}$ School of Medicine, Dire-Dawa University, Dire-Dawa, Ethiopia
}

Email address:

adugnaendale73@gmail.com (A. Endale)

${ }^{*}$ Corresponding author

\section{To cite this article:}

Koyamo Darfiro, Berhanu Erko, Abebe Animut, Adugna Endale. Adherence to Malaria Preventive Measures and Associated Factors in Badewacho District, Southern Ethiopia. International Journal of Biomedical Materials Research. Vol. 4, No. 3, 2016 , pp. 49-57. doi: 10.11648/j.ijbmr.20160403.17

Received: September 28, 2016; Accepted: November 11, 2016; Published: January 3, 2017

\begin{abstract}
Malaria remains a major public health problem in Ethiopia threatening the lives of $68 \%$ of the population. At present, long lasting insecticidal nets and indoor residual spraying are the major malaria prevention and control methods in the country.This study was undertaken to assess adherence to currently available malaria preventive methods its associated factors inBadewacho District, Southern Ethiopia.A community based cross-sectional study was conducted between February and March, 2013. Systematic random sampling method was used to collect data on preventive measures from 138 households through semi-structured questionnaires administered to interviewees during home to home visit. The data was computed using a statistical soft ware SPSS version 16.0. A P-value $<0.05$ and $95 \%$ CI excluding 1 were considered statistically significant.The coverage and the proportion of households with one or more of their members utilizing mosquito nets in the district were $73.2 \%$ and $44.2 \%$ respectively. Net utilization of households with under-five year children was $32.1 \%$. Dirtiness of the nets, lack of appropriate area for hanging, wearing out, and adherence to other preventive measures were mentioned as reasons for not using the nets. Only 63(45.7\%) of the respondents knew that mosquitoes transmit malaria and most households sought treatment in public health facilities.Utilization of mosquito net was significantly associated with previous treatment for malaria in government health institutions and knowledge about malaria prevention methods.Coverage and utilization of the major malaria preventive measures was low in theBadewacho District, Southern Ethiopia. This indicates the necessity of health education to increase the community awareness in utilization of available malaria preventive measures to reduce the disease burden.
\end{abstract}

Keywords: Adherence, Malaria, Preventive Measures, Badewacho District, Ethiopia

\section{Introduction}

Malaria is an infectious disease caused by protozoan parasites belonging to the genus Plasmodium (Rajahram et al., 2012). The disease is mainly transmitted by the bite of female Anopheles mosquitoes (An. mosquitoes) (AntonioNkondjio et al., 2012; Peterson, 2009). There might also be transmission from infected mother to her fetus through placenta (Ouedraogo et al., 2012), during sharing the same hypodermic needle (Chau et al., 2002), and rarely by blood transfusion (Ali et al., 2004).
The disease threatens the lives of more than $50 \%$ of the world's population in over 100 countries and causes serious economic and person-day loses (Modrek et al., 2012; WHO, 2008). It is prevalent in tropical and subtropical regions of sub-Saharan Africa, Central and South America and Asia (Stratton et al., 2008; WHO, 2010).Each year, it causes 225 to 244 million clinical cases and kills up to 1.2 million people worldwide (Murray et al., 2012; WHO, 2010). It takes the greatest toll in young children (Loha and Lindtjørn, 2012b), 
pregnant women (Henry et al., 2012), displaced people (Williams et al., 2013), refugees (Maroushek et al., 2005), non-immune travellers and labourers entering into malarious areas (Askling et al., 2005), and people living in rural areas with limited access to health services (Dev et al., 2004). Currently, malaria is reappearing in areas under elimination of the disease (Atkinson et al., 2012). About $81 \%$ of the cases and $90 \%$ of the deaths due to malaria occur in Africa (Murray et al., 2012; WHO, 2011).

In Ethiopia, malaria is the leading public health problem where an estimated $75 \%$ of the land mass is malarious putting $68 \%$ of the population at risk. It is responsible for more than 2.5 million clinical cases, 460,000 confirmed cases and about 1,169 deaths every year (FMOH, 2006; WHO, 2009). During 2001 - 2005, the number of malaria cases in outpatient departments (OPDs), admissions and inpatient deaths has been increasing with an annual average of 3 million (FMOH, 2006; WHO, 2010). The nationwide child survival study has also documented that malaria affected school attendance by $20 \%$ and contributed to $47 \%$ of child deaths in Ethiopia (FMOH, 2006). In 2009/2010, malaria was the leading cause of OPD visits and health facility admissions (MOH, 2010). Distribution of the disease varies from place to place depending on climate and altitude (Alemu et al., 2011; Woyessa et al., 2012).In Ethiopia, malaria transmission is unstable and characterized by large-scale epidemics occurring every 5-8 years $(\mathrm{MOH}$, 2012). Major transmission occurs from Sep-Dec after the main rainy season followed by Apr-May after short rainy season (MOH, 2012; Woyessa et al., 2012). The country had suffered from the worst malaria epidemics in 1958 with an estimated three million cases and 150,000 deaths $(\mathrm{MOH}$, 2003). Epidemics had also occurred in 1965/66; 1972/1973; $1980 / 81 ; 1987 / 88,1992,1998,2003$, and $2004(\mathrm{MOH}$, 2003; FMOH, 2006).

In Ethiopia,malaria prevention and control activities such as case management, free distribution of long lasting insecticidal nets (LLINs) and IRS targeting epidemic-prone areas up to 2,500m of altitude started in 2005 (MOH, 2008). In 2006, the Federal Ministry of Health launched national five-year strategic plan for malaria prevention and control. The strategy targeted epidemic reduction by early diagnosis and treatment, selective vector control by providing all $\mathrm{HHs}$ with an average of two ITNs in malarious areas, increasing IRS coverage to $60 \%$ in epidemic-prone areas and environmental management, and information, education and communication to transmit all key malaria messages to increase community awareness (FMOH, 2006). The latest national strategic plan of the country $(2011-2015)$ is aimed at eliminating the disease in areas with low malaria transmission and zero deaths due to malaria in moderate and high transmission settings ( $\mathrm{MOH}, 2012)$.

Launching health education is also beneficial in malaria prevention and control (Legesse et al., 2007). The utilization of nets by high risk groups mainly depends on education and training status of $\mathrm{HH}$ heads, and geographical location of HHs. Women's education and training on malaria related topics also have a significant role in the appropriate implementation of control programs including ITN ownership and use (Astatike and Feleke, 2009; Deribew et al., 2012; Hwang et al., 2010). Education status, income of HHs, and their living condition are prime determinant factors of malaria infection risk (Astatike and Feleke, 2009; Bekele, 2012). Education and income have significant association with subjects' knowledge on malaria preventive measures (Legesse et al., 2007).

Early detection and treatment of cases results in reduced disease burden and transmission (Otten et al., 2009). However, its efficacy depends on the correct use and dosage of antimalarial drugs (Kaona and Tuba, 2003). The distribution of ACT highly reduced malaria related morbidity and mortality in Zanzibar (Bhattarai et al., 2007). Delayed presentation to treatment can be reduced by addressing transport cost, decentralization of services and increasing awareness of communities (Getahun et al., 2010).

Malaria is the most common disease in the SNNPR state of Ethiopia in general and in West Badewacho District in particular. The general prevalence of the disease in the region is $5.4 \%$ with its peak $9.9 \%$ in central zones of the region where our study site lays (TCC, 2007). The major outbreaks of malaria occur after the main rainy season and last for about three months (October-December) followed by the minor transmission occurring from April to June (FMOH, 2006). LLINs, IRS, early detection and treatment, environmental management, and health education have been implemented by West Badewacho District Health Office. However, adherence to the controlling methods and its associated factors was not assessed to our knowledge. This study, therefore, was designed to measure adherence to current malaria control measures and its associated factors in the area.

\section{Materials and Methods}

\subsection{Study Area and Population}

A community based cross-sectional study was conducted between February and March, 2013, in Badewacho District, Southern Ethiopia. The district is located $357 \mathrm{~km}$ south of Addis Ababa, in the Great Rift Valley. According to the 2007 population and housing census, the district is projected to have a total population of 98,781 in 2013 . The total HHs was 20,159 with estimated 4.9 family sizes. The climatic condition of the district is generally a sub-humid type with mean annual temperature and rain fall of $17.7^{\circ} \mathrm{C}$ $27^{\circ} \mathrm{C}$ and $1450 \mathrm{~mm}-2100 \mathrm{~mm}$, respectively. Its altitude ranges from1,775 $\mathrm{m}$ in Sapera to 2,195 $\mathrm{m}$ in Koto above sea level.

Data on adherence of the community to the available malaria preventive measures was collected using semistructured questionnaire administered to individuals in selected HHs. All members of the HHs who lived in the selected sub-districts at least for 6 months and volunteered to respond to the questionnaire were included to the study. 


\subsection{Sample Size and Data Collection}

The sample size was calculated using the formula for estimating single proportion; $\mathrm{N}=\mathrm{Z}^{2} \mathrm{PQ} / \mathrm{D}^{2}$. Where; Nis the minimum sample size required, $Z$ is the critical value for a given confidence interval (1.96), Pis expected proportion of the event to be studied (estimated based on findings of previous studies), $\mathrm{Q}=1-\mathrm{P}$ (proportion of the population represented with the sample), Dis margin of error or degree of accuracy desired (0.05). Assumptions utilization rate of mosquito net used to calculate the sample size was $9.9 \%$ (from previous study) $95 \% \mathrm{CI}$ and $5 \%$ of margin of error $=$ 1.96. Accordingly the total sample size was 138 .

Systematic random sampling method was used to select study HHs. The first $\mathrm{HH}$ to be started was determined by using the table of random numbers as a lottery method. Then after, every $7^{\text {th }}$ (sampling interval) HHs was sampled until the sample size allocated for the study was obtained.Head of the selected $\mathrm{HH}$ or the next elder member of the $\mathrm{HH}$ was interviewed.

Data on socio-demographic status, access to health services, knowledge, attitude, and practice of the participants towards malaria preventive measures was collected using semi-structured questionnaires. The questionnaire was initially prepared in English and translated to Amharic prior to the study. Subjects were interviewed by using the local language, Hadiyisa, to minimize complications and increase their confidence in answering questions. The local leaders were used for translation task and indicate directions. During data collection in the field and at the end of each day, the questionnaires were reviewed and checked for completeness, accuracy and consistency by the principal investigator and corrective measures were taken.

\subsection{Data Analysis}

Data was coded on pre-arranged coding sheet by the principal investigator, entered and analyzed using SPSS version 16 statistical software. Tables and graphs were used to present frequencies of relevant findings. The relative contribution of each selected variables to the outcome of interest (adherence to preventive measures) was assessed by using logistic regression. The association between the dependent and independent variables was measured using pvalue and $95 \% \mathrm{CI}$. P-value $<0.05$ and confidence intervals excluding 1 were considered as statistically significant.

\subsection{Ethical Considerations}

Ethical clearance was obtained from the Institutional Review Board of Aklilu Lemma Institute of Pathobiology, Addis Ababa University.Permission to undertake the study in the district was obtained from Badewacho District Health Office. Aim, purpose, benefits and method of the study was explained to the participants and verbal consent was obtained from them. They had the right to be involved or not in the study. The name and address of the interviewees was kept confidential.

\section{Results}

\subsection{Socio-demographic Characteristics of the Study Population}

The number of households included for the study on adherence to current malaria preventive measures was 138 . Most of the interviewees were protestant religion followers. About $73.9 \%, 5.1 \%$ and $10.1 \%$ of the households had high risk groups (under five years children and pregnant women), opening in their house roof, and wall respectively.About $96 \%$ and $75 \%$ of HHs sealed their walls and roofs with mud and corrugated iron sheet, respectively. About $60 \%$ of the study HHs had more than five persons per households (Table 1).

Table 1. Socio-demographic characteristics of study households, Badewacho District, Southern Ethiopia, 2013.

\begin{tabular}{lll}
\hline Variables & $\begin{array}{l}\text { Frequency } \\
\text { (No.) }\end{array}$ & Percent (\%) \\
\hline $\begin{array}{l}\text { Religion } \\
\text { Orthodox }\end{array}$ & 24 & 17.4 \\
$\begin{array}{l}\text { Catholic } \\
\text { Protestant }\end{array}$ & 3 & 2.2 \\
Presence of high risk group in the HH & 111 & 80.4 \\
Present & 102 & 73.9 \\
Absent & 36 & 26.1 \\
The type of house roof & & \\
Thatch & 104 & 75.4 \\
Corrugated iron sheet & 34 & 24.6 \\
The type of the house wall & & \\
$\begin{array}{l}\text { Mud } \\
\text { Thatch }\end{array}$ & 132 & 95.7 \\
$\begin{array}{l}\text { Plant product } \\
\text { Presence of opening in the roof }\end{array}$ & 1 & 0.7 \\
$\begin{array}{l}\text { Present } \\
\text { Absent }\end{array}$ & 5 & 3.6 \\
Presence of opening in the wall & 7 & 5.1 \\
Yes & 131 & 94.9 \\
No & & 10.1 \\
Family size of HH & 14 & 89.9 \\
2-5 persons per HH & 124 & 39.9 \\
6-9 persons per HH \\
more than 9 persons per HH
\end{tabular}

\subsection{Malaria Preventive Measures}

About $44.2 \%$ (61) of the study households head were trained on malaria related topics. Health education was delivered to $102(73.9 \%)$ households through home visiting health professionals and in the health facility. About $73.2 \%$ of the households in the study area had at least one long lasting insecticidal net during the survey (Figure 1).

The utilization rate of mosquito nets the households by one or more of their members a day before the survey was 61(44.2\%). The environmental management activities undertaken among the households were very low. Only $32(23.2 \%)$ of the households interviewed had one or more of their members participated in the community malaria control campaign in their life time. Draining stagnant water, earth fill of open pits, and cleaning the environment were activities undertaken during the campaign. The IRS acceptance rate was high with in the study population (Table 2). About $95 \%$ 
(131) of HHs had IRS in February, 2013. Only two HH owners refused IRS to their houses complaining that the chemical used for IRS facilitates overgrowth of bed bugs and harm their domestic animals. Five HHs lost spraying opportunity due to lack of awareness about the program. Most HHs sought treatment in health facilities. 95\% of HHs had been treated in health institutions for malaria infection previously (Table 2).

Dirtiness of the nets, lack of appropriate area for hanging, wearing out, and adherence to other preventive measures were mentioned as reasons for not using the nets. More than $75 \%$ of the non users complained that the nets were too dirty. About $90 \%$ of HHs kept their LLINs below three years before discarding (figure 3 ).

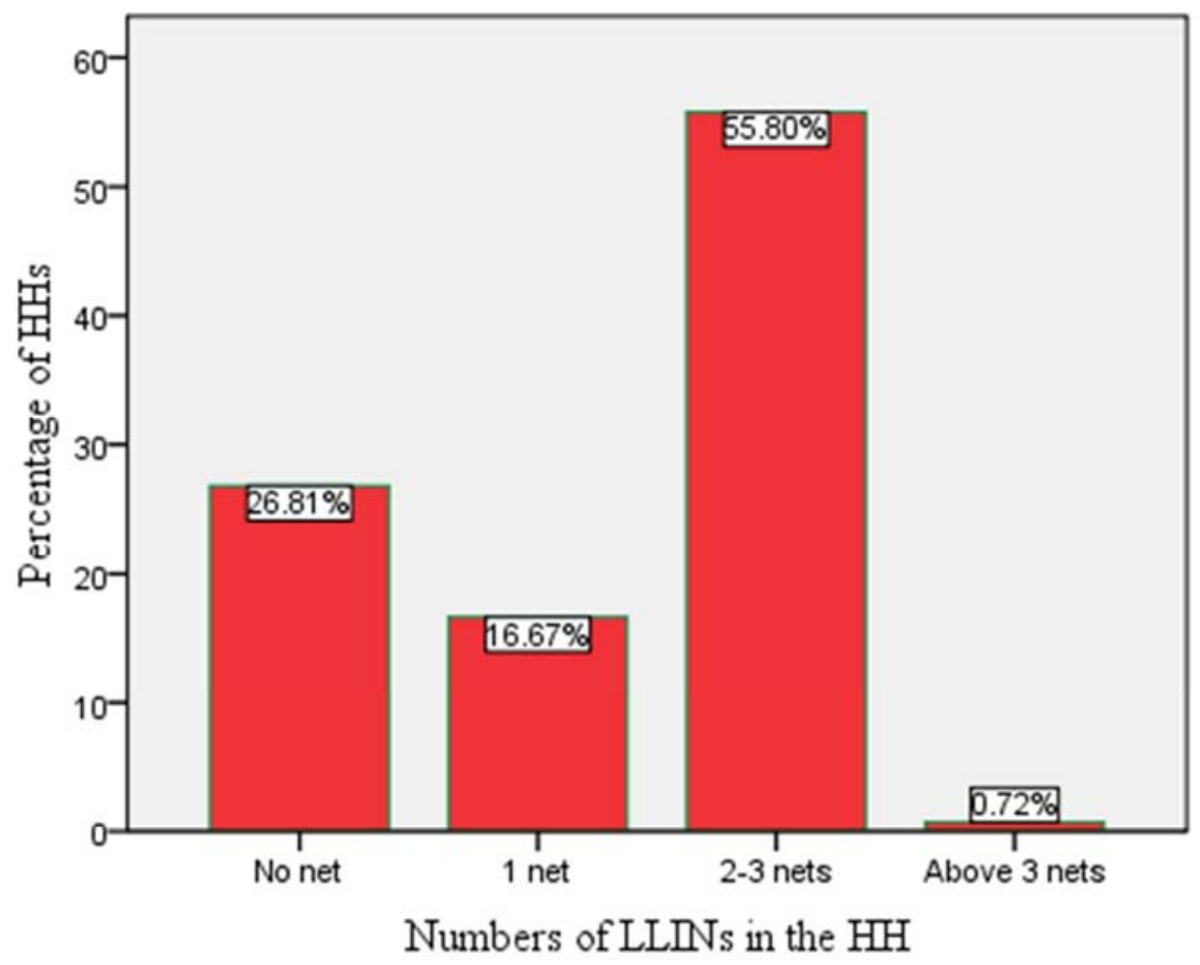

Figure 1. Graph indicating the coverage of LLINs in Badewacho District, Southern Ethiopia, 2013.

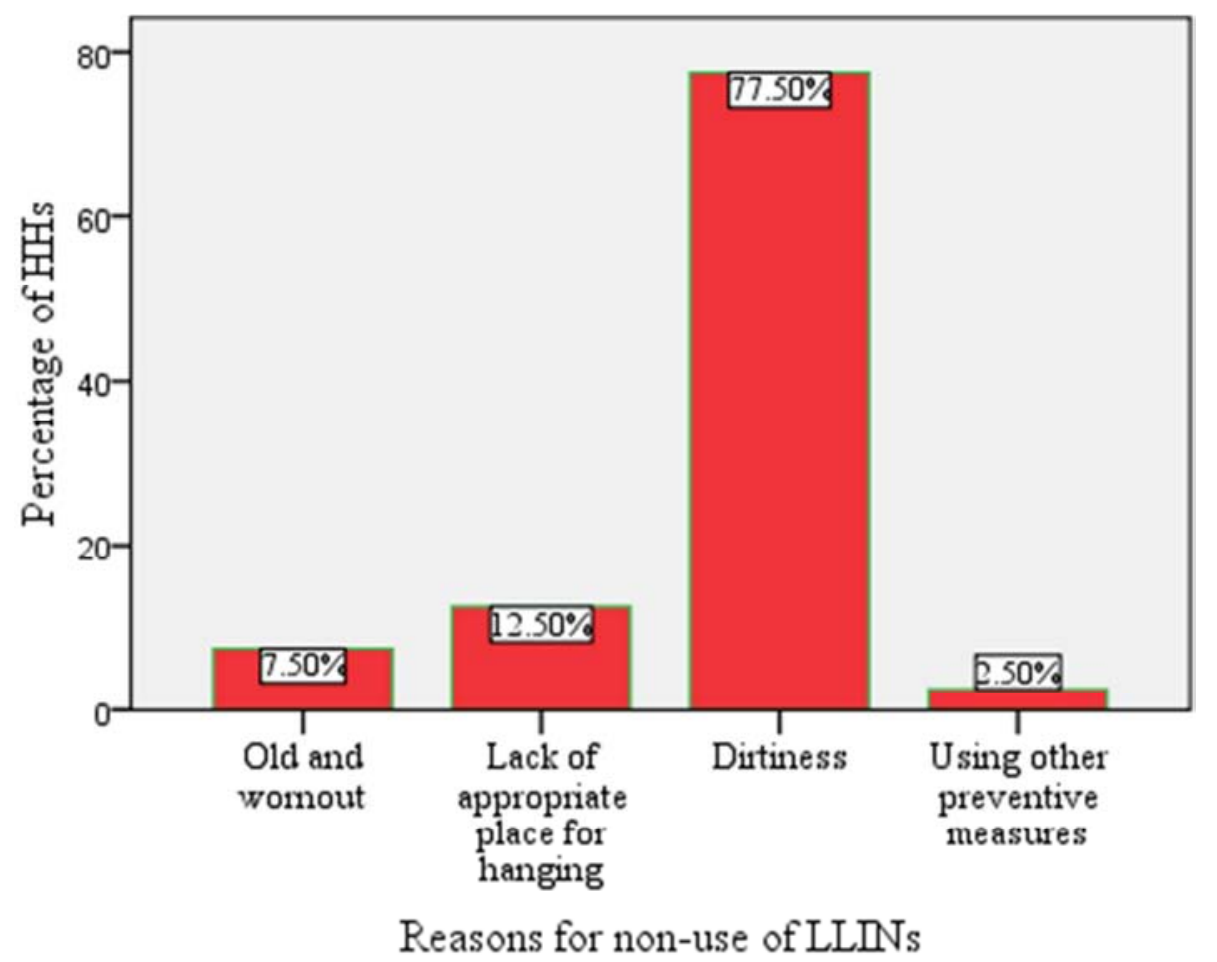

Figure 2. Graph indicating reasons for non-utilization of LLINs in Badewacho District, Southern Ethiopia, 2013. 


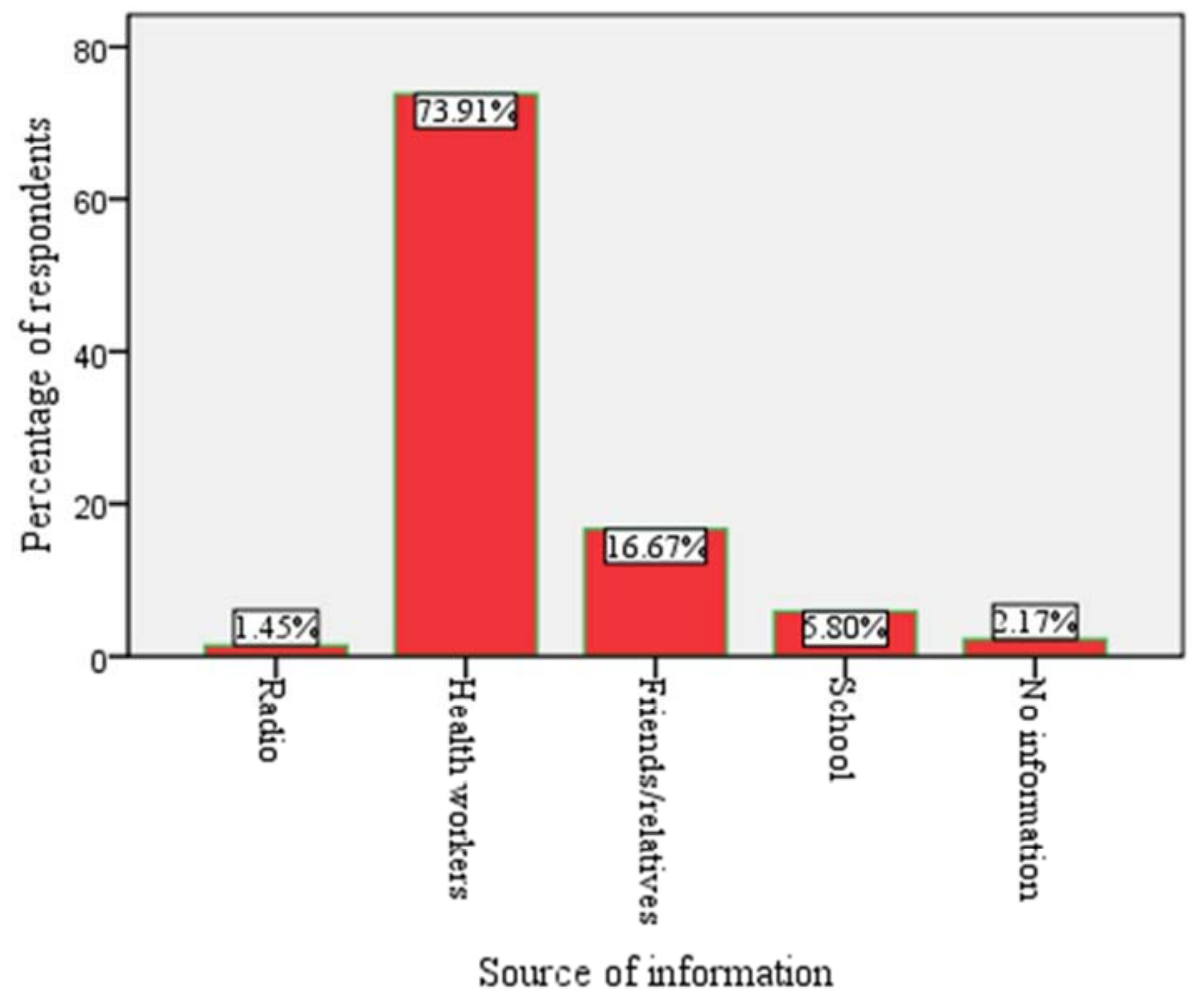

Figure 3. Information sources of interviewees about malaria in Badewacho District, Southern Ethiopia, 2013.

In bivariate analysis, the net utilization in the area was significantly associated with the type of health facility visited by the $\mathrm{HH}$ members previously for treatment $(\mathrm{p}<0.05=$ 0.026 ; 95\% CI: $1.152-9.165)$, participation in community malaria control campaign $(\mathrm{p}<0.05=0.02$; CI: $0.167-0.061)$, wealth status of the HH $(\mathrm{p}<0.05=0.018$; $95 \%$ CI: $1.165-$ 5.251), and knowledge level of interviewees about malaria preventive measures ( $<<0.05=0.006$; 95\% CI: 0.177-0.753). After adjusting for all possible confounding variables, the type of health facility visited for treatment and knowledge level about malaria prevention measures of interviewees become statistically significant. Significant numbers of participants had been utilizing the nets among HHs with previous history of visiting government health institutions (GHIs) and knowledgeable about malaria prevention measures. Family size, presence of high risk groups in $\mathrm{HH}$, training status of $\mathrm{HH}$ heads on malaria related topics, knowledge about malaria transmission and symptoms have no association with insecticide treated net utilization in both bivariate and multivariate logistic regression (Table 3).

Table 2. Adherence of households with malaria preventive measures, Badewacho District, Southern Ethiopia, 2013.

\begin{tabular}{lll}
\hline Variable & Frequency & Percent \\
\hline Participation in environmental management & & \\
Yes & 32 & 23.2 \\
No & 106 & 76.8 \\
Utilization of LLINs previous night & & \\
Yes & 61 & 44.2 \\
No & 77 & 55.8 \\
IRS acceptance & & \\
Yes & 131 & 95 \\
No & 7 & 5 \\
Preferred place for treatment & & \\
Health institutions & 134 & 97.1 \\
Use left over drugs & 4 & 2.9 \\
\hline
\end{tabular}

Table 3. Socio-demographic characteristics and KAP of interviewees and their association withutilization of mosquito nets, Badewacho District, Southern Ethiopia, 2013.

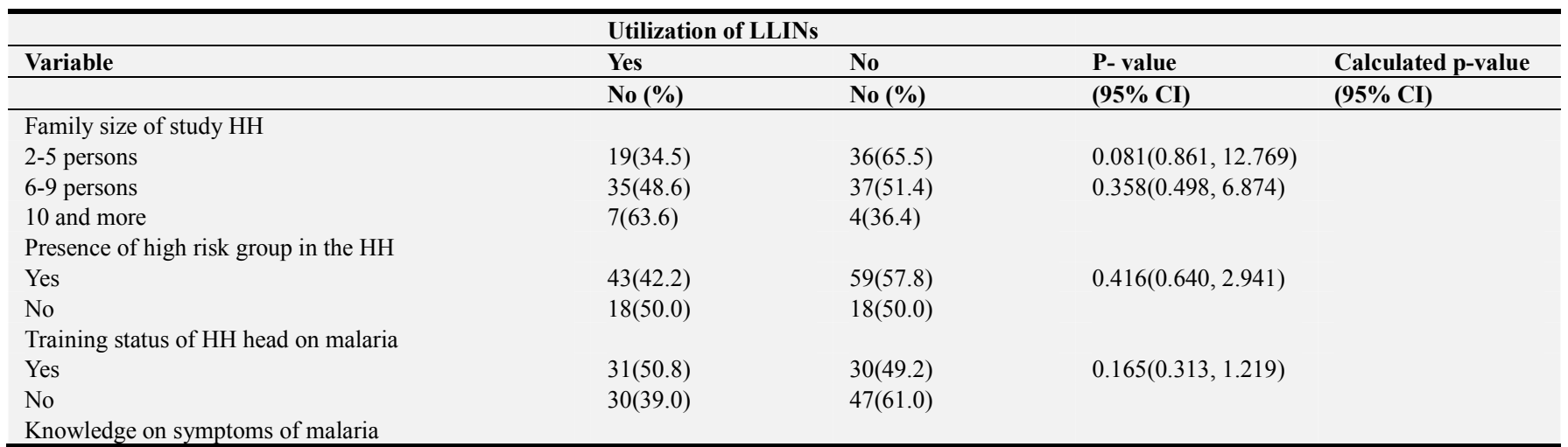




\begin{tabular}{|c|c|c|c|c|}
\hline \multirow[b]{2}{*}{ Variable } & \multicolumn{4}{|c|}{ Utilization of LLINs } \\
\hline & Yes & No & P-value & Calculated p-value \\
\hline & No (\%) & No $(\%)$ & $(95 \% \mathrm{CI})$ & $(95 \% \mathrm{CI})$ \\
\hline Know* & $54(46.2)$ & $63(53.8)$ & $0.280(0.220,1.550)$ & \\
\hline Not know* & $7(33.3)$ & $14(66.7)$ & & \\
\hline \multicolumn{5}{|c|}{ Monthly income of $\mathrm{HH}$ head } \\
\hline Poor & $37(37.8)$ & $61(62.2)$ & $0.018(1.165,5.251)$ & $0.122(0.843,4.268)$ \\
\hline Well & $24(60.0)$ & $16(40.0)$ & & \\
\hline \multicolumn{5}{|c|}{ Knowledge on malaria transmission } \\
\hline Know** & $33(52.4)$ & $30(47.6)$ & & \\
\hline Not know** & $28(37.3)$ & $47(62.7)$ & $0.077(0.935,3.647)$ & \\
\hline \multicolumn{5}{|c|}{ Knowledge on malaria prevention } \\
\hline Know*** & $21(53.2)$ & $18(46.2)$ & $0.006(0.177,0.753)$ & $0.031(0.200,0.925)$ \\
\hline Not know*** & $40(40.4)$ & $59(59.6)$ & & \\
\hline \multicolumn{5}{|c|}{ Place of treatment } \\
\hline GHI & $46(40.0)$ & $69(60.0)$ & $0.026(1.152,9.165)$ & $0.043(1.037,9.383)$ \\
\hline Left over drugs & $2(50.0)$ & $2(50.0)$ & $0.488(0.244,19.276)$ & \\
\hline $\mathrm{GHI}$ and $\mathrm{PHI}$ & $13(68.4)$ & $6(31.6)$ & & \\
\hline \multicolumn{5}{|c|}{ Participation in community malaria control campaign } \\
\hline Yes & $20(62.5)$ & $12(37.5)$ & $0.020(0.167,0.855)$ & $0.072(0.186,1.075)$ \\
\hline No & $41(38.7)$ & $65(61.3)$ & & \\
\hline
\end{tabular}

Nearly $74 \%$ of the interviewees heard about malaria from health professionals followed by $23(16.7 \%), 8(5.8 \%)$ and $2(1.4 \%)$ who got information from friends/relatives, school and radio respectively. The rest $3(2.2 \%)$ have no information at all (Figure 3).

Table 4. Reported knowledge of respondents about malaria preventive measures in Badewacho District, Southern Ethiopia, 2013.

\begin{tabular}{lll}
\hline Variable & Frequency & Percent \\
\hline Early detection and treatment & 9 & 6.5 \\
Draining stagnant water & 4 & 2.9 \\
Clearing the vegetation & 5 & 3.6 \\
Using mosquito nets & 32 & 23.2 \\
Non preventable disease & 2 & 1.4 \\
Personal hygiene and environmental sanitation & 46 & 33.3 \\
Taking antimalarial drugs and using mosquito nets & 13 & 9.4 \\
IRS and using mosquito nets & 3 & 2.2 \\
Draining stagnant water and using mosquito nets & 7 & 5.1 \\
Fumigation of leaving homes, personal & & \\
hygiene and environmental sanitation & 1 & 0.7 \\
Treatment, IRS and draining stagnant water & 2 & 1.4 \\
Treatment, draining stagnant water and using & 6 & 4.3 \\
mosquito nets & & \\
Treatment, IRS, draining stagnant water and using & 8 & 5.8 \\
nets & & \\
\hline
\end{tabular}

The knowledge of respondents about malaria transmission, prevention and control measure was not considerable even among HHs with trained heads (Table 4). Only 63(45.7\%) of the respondents knew that mosquitoes transmit malaria. Dirt surrounding was mentioned as a risk for malaria transmission by $32(23.2 \%)$ of the respondents. $37(26.8 \%)$ of the interviewees perceived that poor personal hygiene, malnutrition, cold weather, contaminated food, exposure to sun, in combination with dirt surrounding, each other, or alone can enhance malaria transmission. The remaining $6(4.3 \%)$ refused to respond for these questions. Minor malaria transmission routes such as transmission from infected mother to her fetus through placenta, sharing of needles to inject intravenous drugs and blood transfusion were reported with none of the respondents.
$46(33.3 \%)$ of the respondents thought personal hygiene and environmental sanitation prevent malaria. Utilization of mosquito nets and early detection and treatment were recognized as malaria preventive measures by $32(23.2 \%)$ and $9(6.5 \%)$ of respondents respectively (Table 4$)$.

Majority of respondents mentioned at least three of the common clinical symptoms of malaria such as fever, vomiting, chills, shivering; headache, backache, joint pain, thirsty and loss of appetites were reported by the study population (table 5).

Table 5. The knowledge level about malaria symptoms in Badewacho district, southern Ethiopia, 2013.

\begin{tabular}{lll}
\hline & Frequency (No.) & Percent \\
\hline Know a single symptom & 1 & 0.7 \\
Know two of the symptoms & 15 & 10.8 \\
Know three of the symptoms & 65 & 47.1 \\
Know four of symptoms & 35 & 25.4 \\
Know five of the symptoms & 15 & 10.9 \\
Know six of symptoms & 1 & 0.7 \\
Not know any symptom & 6 & 4.3 \\
\hline
\end{tabular}

\section{Discussion}

Early diagnosis and treatment of cases, LLINs and indoor spraying with residual insecticides are being used as the major preventive measures of malaria in Ethiopia $(\mathrm{MOH}$, 2012). Selective vector control with LLINs, IRS, and early detection and treatment with ACT (Otten et al., 2009; Okell et al., 2012; Loha and Lindtjørn, 2012a)recognized as effective methods of malaria prevention and control. Environmental management has also been used as effective operation as malaria control in collaboration with other methods (Castro et al., 2009). Information, education, and communication too have significant role in malaria prevention and control strategies (MOH, 2012).

The present study revealed that $73.2 \%$ of $\mathrm{HHs}$ in Badewacho District had at least one net which was lower than the report by Baume et al. (2009). The coverage can be 
assumed as under achievement relative to FMOH target for 2012 (MOH, 2012). However, it was relatively higher than in 2009 which was $67.5 \%$. The coverage of the nets in Badewacho District was similar to that of Arbaminch area during 2007(75.1\%) (Astatike and Feleke, 2009; Bekele, 2012). It was also nearly the same to the report from Ruanda in 2010 (76\%) (Karema et al., 2012). This study indicates that the number of nets available in some of the study HHs were not sufficient for the respective number of family members (MOH, 2012).

Utilization rate of mosquito nets in Badewacho District HHs, by one or more of their members, a day before the survey was $44.2 \%$. This utilization rate was lower compared to that of the Arbaminch area and Assosa Zone of Western Ethiopia (Astatike and Feleke, 2009; Legesse et al., 2007). As documented by Astatike and Feleke (2009), Legesse et al. (2007), and Batisso et al. (2012), the proportions of HHs utilizing the nets were $60 \%, 71 \%$ and $58 \%$ respectively which were lower compared to Badewacho District. Utilization of the nets was significantly affected by the type of health facility visited during the previous infection and knowledge of interviewees about malaria prevention measures. This strengths the need for provision of malaria related health educations in governmental health facilities besides treatment. In this study, it was reported that, the majority of respondents abstained from utilizing the nets because of dirtiness of the net unlike in the previous one which was due to wearing out (Batisso et al., 2012).

Maintaining the recommended shelf life of LLINs was mandatory in preserving the coverage and utilization of it (Batisso et al., 2012). In this study, 90\% of HHs discarded their LLINs without utilizing at least for three years. This strictly contradicts with the idea of FMOH (MOH, 2012).

IRS is one of the major malaria preventive measures recommended in areas with high incidence rate, high malaria transmission, occurrence of epidemic outbreaks, and with natural or man-made disasters (MOH, 2012). 131(95\%) of study HHs were sprayed during the previous IRS program. This was comparable to the coverage described by Beer et al. (2013) in Tanzania. Malaria was also still the problem of the study area. This might be due to the loss in potency of chemicals with time or insecticide resistance (Balkew et al., 2012; Bradley et al., 2012).

The knowledge about malaria transmission and preventive measures was suggested in previous studies to minimize malaria burden (Tobgay et al., 2013). This study indicated that the proportion of respondents knowledgeable about the route of malaria transmission and its preventive strategies were $45.7 \%$ and $28.3 \%$ respectively. There was no much difference in the knowledge about malaria transmission among the residents of Badewacho District, Assosa Zone of Western Ethiopia, and in some highland areas of Ethiopia where malaria has been recently introduced. But, the respondents knowledge about the preventive strategies of the disease was lower than that of Assosa with reported percentage of 48 (Legesse et al., 2007; Legesse and Deressa, 2009).

Awareness of Badewacho District residents on the symptoms of the disease was relatively high. This might be due to frequent occurrence of the disease in the study population. $84 \%$ of respondents knew three or more of major malaria symptoms such as fever, vomiting, chills, shivering, headache, backache, joint pain, thirsty and loss of appetite. Most of the respondents preferred health institutions for malaria treatment. The knowledge level of respondents was similar to that of Adami Tulu District but the preference of health institution for treatment was higher in this case (Deressa, 2007).

Despite the limited knowledge, attitude and practices about malaria prevention and control measures, $95 \%$ of the houses were sprayed during the previous IRS program. Small proportion of the HHs left without spraying due to reported reasons and the result was similar to that of Tanzania (Kaufman et al., 2012). The insecticides used for the program were carbamate insecticides specially propoxur which was previously recommended by FMOH and other stake holders (MOH, 2012; Yewhalaw et al., 2011). One of the limitations of this study was that we used a cross-sectional study design, which is a snapshot of a single point in time and misses the seasonal trends of mosquito net utilization rate in the study area.

\section{Conclusions}

The community adherence to current malaria preventive measures was generally low in the study site compared to the national target. The coverage and utilization of LLINs, and participation in environmental management activities were generally low. The insights gained from this study suggest a number of issues to be considered in the area of malaria prevention and control strategies. The scheme to elongate the shelf life and replace worn out nets should be launched in all levels of stake holders. Community mobilization and advocacy should be strengthened to increase the community's awareness on malaria transmission and preventive measures.

\section{References}

[1] Alemu, A., Tsegaye, W., Golassa, L., Abebe, G., 2011. Urban malaria and associated risk factors in Jimma town, South-West Ethiopia. Malar J 10, 173.

[2] Alemu, G., 2006. Prevalence of Malaria and its influencing factors in Awassa District, Southern Ethiopia. http://www.pdf4free.com.

[3] Ali, M.S.M., Kadaru, A.A.I.G.M. Y., Mustafa, M.S., 2004. Screening blood donors for malaria parasite in Sudan. Ethiop J Health Dev. 18(2), 70-74.

[4] Animut, A., Balkew, M., Gebre-Michael, T., Lindtjørn, B., 2013. Blood meal sources andentomological inoculation rates of Anophelines along a highland altitudinal transect in southcentral Ethiopia. Malar J 12, 76.

[5] Antonio-Nkondjio, C., Defo-Talom, B., Tagne-Fotso, R., Tene-Fossog, B., Ndo, C., Lehman,L.G., Tchuinkam, T., Kengne, P., Awono-Ambene, P., 2012. High mosquito burden and malaria transmission in a district of the city of Douala, Cameroon. BMC Infect Dis 12, 275. 
[6] Askling, H.H., Nilsson, J., Tegnell, A., Janzon, R., Ekdahl, K., 2005. Malaria Risk in Travelers. J Emerg Infect Dis 11(3), 2005.

[7] Atkinson, J.A., Johnson M. L., Wijesinghe, R., Bobogare, A., Losi, L., O’Sullivan, M., Yamaguchi, Y., Kenilorea, G., Vallely, A., Cheng, Q., Ebringer, A., Bain, L., Gray, K., Harris, I., Whittaker, M., Reid, H., Clements, A., Shanks, D., 2012. Operational research to inform a sub-national surveillance intervention for malaria elimination in Solomon Islands. Malar J 11, 101.

[8] Balkew, M., Getachew, A., Chibsa, S., Olana, D., Reithinger, R., Brogdon, W., 2012. Insecticide resistance: a challenge to malaria vector control in Ethiopia.Malar J 11(1), 139.

[9] Batisso, E., Habte, T., Tesfaye, G., Getachew, D., Tekalegne, A., Kilian, A., Mpeka, B., Lynch, C., 2012. A stitch in time: a cross-sectional survey looking at long lasting insecticidetreated bed net ownership, utilization and attrition in SNNPR, Ethiopia. Malar J 11, 183.

[10] Baume, C.A., Reithinger, R., Woldehanna, S., 2009.Factors associated with use and non-use of mosquito nets owned in Oromia and Amhara Regional States, Ethiopia.Malar J 8, 264.

[11] Beer, N., Ali, A.S., Shakely, D., Elfving, K., Al-Mafazy, A.H., Msellem, M., Petzold, M., Björkman, A., Källander, K., 2013.High effective coverage of vector control interventions in children after achieving low malaria transmission in Zanzibar, Tanzania. Malar J 12, 38.

[12] Bekele, D., Belyhun, Y., Petros, B., Deressa, W., 2012. Assessment of the effect of insecticide-treated nets and indoor residual spraying for malaria control in three rural kebeles of Adami Tulu District, South Central Ethiopia. Malar J 11, 127.

[13] Bhattarai, A., Ali, A.S., Kachur, S.P., Martensson, A., Abbas, A.K., Khatib, R., Al-mafazy, A., Ramsan, M., Rotllant, G., Gerstenmaier, J.F., Molteni, F., Abdulla, S., Montgomery, S.M., Kaneko, A., Bjorkman, A., 2007. Impact of artemisininbased combination therapy and insecticide-treated nets on malaria burden in Zanzibar. PLoS Med 4(11): e309.,doi:10.1371/journal.pmed.0040309.

[14] Bradley, J., Matias, A., Schwabe, C., Vargas, D., Monti, F., Nseng, G. and Kleinschmidt, I., 2012. Increased risks of malaria due to limited residual life of insecticide and outdoor biting versus protection by combined use of nets and indoor residual spraying on Bioko Island, Equatorial Guinea. Malar J $11,242$.

[15] Castro, M.C, Tsuruta, A., Kanamori, S., Kannady, K., Mkude, S., 2009. Community-based environmental management for malaria control: evidence from a small-scale intervention in Dares Salaam, Tanzania. Malar J 8, 57.

[16] Chau, T.T.H., Mai, N.T.H., Phu, N.H., Luxemburger, C., Chuong, L.V., Loc, P.P., Trang, T.T.M., Vinh, H., Cuong, B.M., Waller, D.J., Sinh, D.., Day, N. P.J., Hien, T.T., White, N.J., 2002.Malaria in injection drug abusers in Vietnam. CID $34,1317-1322$.

[17] Deressa, W., Olana, D., Chibsa, S., 2003. The retirement of malaria control workers as a critical problem for vector control in Oromia, Ethiopia. Ethiop J Health Dev. 17(1), 79-83.

[18] Deribew, A., Birhanu, Z., Sena, L., Dejene, T., Reda, A.A., Sudhakar, M., Alemseged, F., Tessema, F., Zeynudin, A., Biadgilign, S., Deribe, K., 2012. The effect of household heads training about the use of treated bed nets on the burden of malaria and anaemia in under-five children: a cluster randomized trial in Ethiopia. Malar J 11, 8.

[19] Dev, V., Phookan, S., Sharma, V.P., Anand, S.P., 2004. Physiographic and Entomologic risk factors of malaria in Assam, India. Am. J. Trop. Med. Hyg. 71(4), 451-456.

[20] FMOH, 2006. National Five-Year Strategic Plan for Malaria Prevention \& Control in Ethiopia 2006-2010. Addis Ababa, Ethiopia.

[21] Getahun, A., Deribe, K., Deribew, A., 2010. Determinants of delay in malaria treatment- seeking behaviour for under-five children in south-west Ethiopia: a case control study. Malar $J$ 9, 320 .

[22] Henry, O.J., Lagoro, K.D., Garimoi, C.O., 2012. Prevalence of malaria and treatment seeking behaviors among pregnant women in post conflict internally displaced persons' camps in Gulu District. ISRN Public Health, doi:10.5402/2012/164935.

[23] Hwang, J., Graves, P.M., Jima, D., Reithinger, R., Kachur, S.P., Ethiopian MIS Working Group, 2010. Knowledge of malaria and its association with malaria-related behavioursresults from the malaria indicator survey, Ethiopia, 2007. PLOS ONE 5, 7.

[24] Kaona, F.A.D., Tuba, M., 2003. Improving ability to identify malaria and correctly use chloroquine in children at household level in Nakonde District, Northern Province of Zambia. Malar J 2, 43.

[25] Karema, C., Aregawi, M.W., Rukundo, A., Kabayiza, A., Mulindahabi, M., Fall, I.S., Gausi, K.,Williams, R.O., Lynch, M., Cibulskis, R., Fidele, N., Nyemazi, J.P., Ngamije, D., Umulisa, I., Newman, R., Binagwaho, A., 2012.Trends in malaria cases, hospital admissions and deaths following scaleup of anti-malarial interventions, 2000-2010, Rwanda. Malar $J 11,236$.

[26] Kaufman M. R., Rweyemamu, D., Koenker, H., Macha, J., 2012. "My children and I will no longer suffer from malaria": a qualitative study of the acceptance and rejection of indoor residual spraying to prevent malaria in Tanzania. Malar J 11, 220.

[27] Legesse, M., Deressa, W., 2009. Community awareness about malaria, its treatment and mosquito vector in rural highlands of central Ethiopia.Ethiop J Health Dev. 23(1), 40-47.

[28] Legesse, Y., Tegegn, A., Belachew, T., Tushune, K., 2007. Knowledge, attitude and practiceabout malaria transmission and its preventive measures among households in urban areas of Assosa Zone, Western Ethiopia. Ethiop J Health Dev.21 (2), 157-165.

[29] Loha, E., Lindtjørn, B., 2012a. Effect of bed nets and indoor residual spraying on spatio-temporal clustering of malaria in a village in South Ethiopia: a longitudinal study. Malar $J$ 11(Suppl 1), 66.

[30] Loha, E., Lindtjørn, B., 2012b. Predictors of Plasmodium falciparum malaria incidence in Chano Mille, South Ethiopia: A Longitudinal Study. Am. J. Trop. Med. Hyg. 87(3), 450-459.

[31] Maroushek, S.R., Aguilar, E.F., Stauffer, W., Abd-Alla, M.D., 2005. Malaria among Refugee Children at Arrival in the United States. Pediatr Infect DisJ 24, 450-452.

[32] MOH, 2003. Malaria Prevention and control Extension Package. Federal Democratic Republic of Ethiopia, Addis Ababa, Ethiopia. 
[33] MOH, 2008. Ethiopia malaria indicator survey 2007.Federal democratic republic of Ethiopia, Addis Ababa.

[34] MOH, 2012. National malaria guidelines. Federal democratic republic of Ethiopia $3^{\text {rd }}$ edition, Addis Ababa, Ethiopia.

[35] Murray, C.J.L., Rosenfeld, L.C., Lim, S.S., Andrews, K.G., Foreman, K.J., Haring, D., Fullman, N., Naghavi, M., Lozano, R., Lopez A.D., 2012. Global malaria mortality between 1980 and 2010: a systematic analysis. Lancet 379, 413-31.

[36] Okell, L.C., Paintain, L.S., Webster, J., Hanson, K., Lines, J., 2012.From intervention to impact: modelling the potential mortality impact achievable by different longlasting, insecticide-treated net delivery strategies.Malar $J$ 11, 327.

[37] Otten, M., Aregawi, M., Were, W., Karema, C., Medin, A., Bekele, W., Jima, D., Gausi, Khoti., Komatsu, R., Korenromp, E., Low-Beer, D., Grabowsky, M., 2009. Initial evidence of reduction of malaria cases and deaths in Rwanda and Ethiopia due to rapid scale-up of malaria prevention and treatment. Malar J 8, 14.

[38] Ouedraogo, A., Tiono, A.B., Diarra, A., Bougouma, E.C.C., Nebie, I., Konate, A.T., Sirima, S.B., 2012. Transplacental transmission of plasmodiumfalciparum in a highly malaria endemic area of Burkina Faso. $J$ of Trop Med, doi:10.1155/2012/109705.

[39] Peterson, A.T., 2009. Shifting suitability for malaria vectors across Africa with warming climates. BMC Infect Dis 9, 59.

[40] Rajahram, G.S., Barber, B.E., William, T., Menon, J., Anstey, N.M., Yeo, T.W., 2012. Deaths due to Plasmodium knowlesi malaria in Sabah, Malaysia: Association with reporting as Plasmodium malariae and delayed parenteral artesunate. Malar J 11, 284.

[41] Stratton, L, O’Neill, M.S., Kruk, M.E., Bell, M.L., 2008.The persistent problem of malaria: Addressing the fundamental causes of a global killer. Social Sc \& Med 67, 854-862.
[42] TCC, 2007. Report on prevalence and risk factors for malaria and trachoma; a household survey in Amhara, Oromia and Southern Nations, Nationalities and Peoples' Regions, Ethiopia.

[43] Tobgay, T., Pem, D., Dophu, U., Dumre, S.P., Na-Bangchang, K., Torres, C.E., 2013. Community-directed educational intervention for malaria elimination in Bhutan: quasiexperimental study in malaria endemic areas of Sarpang district. Malar J 12, 132.

[44] WHO, 2008. World malaria report. Global Malaria Programme, Geneva, Switzerland. Availablefrom: http://www.who.int/malaria/wmr2008/malaria2008.

[45] WHO, 2009. World malaria report. Global Malaria Programme, Geneva, Switzerland.

[46] WHO, 2010. World malaria report.Global Malaria Programme, Geneva, Switzerland.

[47] WHO, 2011. World malaria report.Global Malaria Programme, Geneva, Switzerland.

[48] Williams, H.A., Hering, H., Spiegel, P., 2013.Discourse on malaria elimination: where do forcibly displaced persons fit in these discussions?Malar J 12, 121.

[49] Woyessa, A., Deressa, W., Ali, A., and Lindtjørn, B., 2012. Prevalence of malaria infection in Butajira area, south-central Ethiopia. Malar J 11, 84.

[50] Woyessa, A., Gebre-Micheal, T., Ali, A., 2004. An indigenous malaria transmission in the outskirts of Addis Ababa, Akaki Town and its environs. Ethiop J Health Dev. 18(1), 2-7.

[51] Yewhalaw, D., Wassie, F., Steurbaut, W., Spanoghe, P., Van Bortel, W., Denis, L., Tessem, D. A., Getachew, Y., Coosemans, M., Duchateau, L., Speybroeck, N., 2011. Multiple insecticide resistance: An impediment to insecticidebased malaria vector control program. PLoS ONE 6(1), doi:10.1371/journal.pone.001606. 